\title{
High risk of suicide among high-school learners in uMgungundlovu District, KwaZulu-Natal Province, South Africa
}

\author{
N Khuzwayo, ${ }^{1} \mathrm{PhD} ;$ M Taylor, ${ }^{2} \mathrm{PhD} ;$ C Connolly, ${ }^{2} \mathrm{MPH}$ \\ ${ }^{1}$ Discipline of Rural Health, School of Nursing and Public Health, College of Health Sciences, University of KwaZulu-Natal, Durban, South Africa \\ ${ }^{2}$ Discipline of Public Health Medicine, School of Nursing and Public Health, College of Health Sciences, University of KwaZulu-Natal, Durban, \\ South Africa
}

Corresponding author: N Khuzwayo (khuzwayone@ukzn.ac.za)

\begin{abstract}
Background. Worldwide, suicide affects the most vulnerable populations, including adolescents and young adults. It is estimated that suicide will contribute more than $2 \%$ to the global burden of disease by 2020. Information about the prevalence of suicidal behaviour and the sociodemographic characteristics and risk factors associated with suicide in the South African (SA) rural context is important for local and national policy and contributes to global understanding of the phenomenon.

Objective. To investigate key demographic factors and behaviours associated with planning and attempting suicide among high-school learners. Methods. In a cross-sectional study, we used stratified random sampling to select 16 schools in uMgungundlovu District, KwaZulu-Natal Province, SA. All grade 10 learners $(N=1759)$ at these schools completed a self-administered questionnaire (Centers for Disease Control and Prevention (CDC) Youth Risk Behavior Surveillance System). Data analysis was carried out with Stata 13 statistical software using generalised estimating equations.

Results. In total, 222 learners (12.6\% of the 1 759) had made plans to attempt suicide during the previous 12 months, 261 (14.8\%) had actually attempted suicide, and 218 attempts had resulted in the learner being treated by a doctor or nurse $(12.4 \%)$. The risk of planning suicide increased with age. For male learners, being threatened with a weapon on school property (adjusted odds ratio (AOR) 3.7, 95\% confidence interval (CI) $1.9-7.1 ; p<0.01$ ) or bullied through Facebook or WhatsApp (AOR 3.1, 95\% CI $1.5-7.1 ; p<0.01$ ) significantly increased the likelihood of making a suicide attempt that resulted in treatment by a doctor or nurse. For female learners, engaging in risk behaviours increased this likelihood, risk factors including being physically hurt by someone they were dating ( $1-3$ times AOR 3.3, 95\% CI $1.9-5.7$; $p<0.01$, $\geq 4$ times AOR 10.0, 95\% CI $2.5-40.2$ ( $p<0.01$ ) and number of drinks consumed in the past month (AOR 2.0, 95\% CI 1.4 - 3.0; $p<0.01$ ).

Conclusions. The prevalence of suicide attempts among these SA learners was high and was influenced by multiple factors. Routine surveillance systems are urgently required to develop context-based interventions for male and female learners at uMgungundlovu District rural high schools.
\end{abstract}

S Afr Med J 2018;108(6):517-523. DOI:10.7196/SAMJ.2018.v108i6.12843

In South Africa (SA), suicide has become a significant public health problem..$^{[1,2]}$ Suicide is defined as the intentional act of ending one's life. ${ }^{[3]}$ The average rate of suicide in SA in 2012 was 17.2 per 100000 ( $8 \%$ of all deaths). ${ }^{[4]}$ A survey by the South African Medical Research Council showed that one in five adolescents considered suicide in 2013, but these estimates were considered unreliable, as the majority of cases are not reported. ${ }^{[5]}$ However, a Statistics South Africa report on mortality and causes of death in 2015 showed that $~ 125$ deaths of young people aged 14 - 24 years were due to intentional self-harm, including self-poisoning, drowning, strangulation and jumping from a high place. ${ }^{[6]}$ In contrast, a study investigating the association between traumatic events and suicidal behaviour in SA found hanging to be the most frequently employed method of suicide, followed by shooting, gassing and burning. ${ }^{[2]}$ A study that aimed to identify the levels and sex-specific determinants of self-harm mortality among youth in SA found higher rates in males but than females, and noted the prevalence of self-harm mortality in pregnant females as of concern. ${ }^{[7]}$

In $\mathrm{SA}$, suicides are required to be reported to the South African Police Service and hospitals, but owing to insufficient training of police officers in taking a detailed history and lack of forensic training of medical practitioners, the causes of death are often not clear. ${ }^{[8]}$
Of a population of $>54$ million South Africans, $18.5 \%$ are aged 10 19 years and $24 \% 15-24$ years. $^{[2]}$ Adolescence is a critical transitional period that includes the biological changes of puberty and the need to negotiate key developmental tasks. ${ }^{[2]}$ Adjusting to increased independence and normative experimentation may be difficult for high-school learners owing to various social, psychological and contextual factors, the developmental challenges they experience and the risks to which they are exposed ${ }^{[2]}$ Research on risk behaviours shows that many factors influence suicide attempts among young people, including alcohol abuse, being threatened by someone with a weapon, bullying and previous suicide attempts, which have all been associated with a high prevalence of suicide and suicidal ideation among adolescents. ${ }^{[5,8]}$ Substance abuse has been used by learners as a mechanism to help cope with bullying at school. ${ }^{[9]}$ In SA, studies on school violence show that adolescents who are involved in bullying, either as victims or as perpetrators, are more likely to be socially isolated than those who are not involved, since they may lack a sense of belonging. ${ }^{[10]}$ Rates of both physical and cyber bullying among learners have been reported to be high. ${ }^{[1,11]}$ A national survey of violence at school conducted in 2013 indicated that $\sim 24 \%$ of learners were bullied on school property. ${ }^{[12]}$ A survey conducted in uMgungundlovu District in 2016 showed similar results. ${ }^{[13]}$ This 
is of concern, because experiences of school bullying have lifelong consequences that can increase suicidality. ${ }^{[14]}$ Unfortunately, teachers are not equipped to work with young people who are bullied at school. Further, many SA government schools lack counsellors trained in mental healthcare.

In SA, youth risk behaviours are currently monitored by the Youth Risk Behavior Surveillance System developed by the US Centers for Disease Control and Prevention (CDC). This surveillance instrument is used globally. In SA, three rounds of surveillance were conducted in high schools, in 2002, 2008 and 2013. ${ }^{[15]}$ These surveys reported similar rates of suicide, in that $19 \%$ of the sample of school learners reported that they had considered attempting suicide, $16 \%$ reported having made a plan to commit suicide and $17 \%$ had made one or more attempts. Similar findings were reported by the 2012 Youth Risk Behavior Surveillance in the USA. ${ }^{[10]}$ In Malawi, a study that examined the behavioural correlates of suicide attempts among adolescents in the previous 12 months found that $7.15 \%$ of adolescents had attempted suicide at least once and that $5.75 \%$ had made two or more attempts. ${ }^{[16]}$

\section{Objective}

To report on key demographic factors and risk behaviours that were associated with planned suicide, attempted suicide and attempted suicide resulting in treatment among high-school learners.

\section{Methods}

This was a cross-sectional study. The KwaZulu-Natal provincial Department of Education and district offices gave permission for schools in each of the six local municipalities to be randomly selected, and 16 high schools were enrolled. Meetings with principals were arranged to introduce the study, and information sessions were conducted with all the grade 10 learners. Before data collection, information sheets describing the study were sent home to parents/ guardians, after which written informed consent from parents and learners aged $\geq 18$ years and assent from learners aged $\leq 17$ years was obtained. Learners completed a self-administered questionnaire (CDC Youth Risk Behavior Surveillance System), which was supervised in a classroom by the principal investigator (NK) and took about an hour. All grade 10 learners in each of the 16 schools were invited to participate; there were 8 refusals and 20 absentees.

Ethical approval was obtained from the University of KwaZuluNatal Biomedical Research Ethics Committee (ref. no. BE342/14). Data analysis was carried out using Stata 13 statistical software (StataCorp, USA). Descriptive analyses were used for the sample characteristics. The $\chi^{2}$ test was used to determine associations between having ever made a plan to attempt suicide, an actual suicide attempt and a suicide attempt that resulted in treatment by a doctor or nurse, and key categorical demographic variables. Where statistical significance for variables in the bivariate analyses was $p<0.2$, multivariate analysis was undertaken and the adjusted odds ratio (AOR) and $95 \%$ confidence intervals (CIs) are reported. A statistical significance level of $p<0.05$ was adopted for all the analyses. A generalised estimating equation model was used to adjust for the possible correlation of students within schools.

\section{Results \\ Demographic characteristics of the high-school learners (Table 1)}

The demographic characteristics of these learners have been reported previously. ${ }^{[13]}$ In brief, there were similar numbers of male and female participants, but the females were significantly younger. Analysis of the household structure indicated that few learners lived with both biological parents, and in $39.8 \%$ of the households, the household head was not formally employed. Most learners lived in rural areas, many in traditional Zulu homesteads consisting of a fenced yard with separate houses or traditional round houses built of blocks or wattle and daub.

The prevalence of suicidal ideation and suicidal behaviour in the learners is graphically represented in Fig. 1.

\section{Planning and attempting suicide (Table 2)}

Of the learners in this study, 786 (44.7\%) had felt so sad and hopeless for $\geq 2$ weeks in the previous 12 months that they had stopped their normal activities. Overall, during the past 12 months, 370 (21.0\%) of the participants had considered attempting suicide, 220 (13.3\%) had made plans to attempt suicide, and 256 (15.2\%) had actually attempted suicide. Of the suicide attempts, 175 by females and 42 by males had resulted in treatment by a doctor or a nurse. Both male and female students reporting depression were more likely to attempt suicide than those who did not report it (AOR 7.2, 95\% CI 4.6 - 11.2; $p<0.001$ and AOR 11.0, 95\% CI $7.4-16.4 ; p<0.001$, respectively).

Two demographic characteristics were associated with both making a suicide plan and actual suicide attempts. Learners aged $16-17$ years (15.4\%) (adjusted odds ratio (AOR) 2.0, 95\% CI $1.4-2.8$; $p<0.01$ ) had an increased risk of planning a suicide attempt compared with those aged 13 - 15 years. The odds of making a suicide plan (AOR 5.6, 95\% CI 3.6 - 8.7; $p<0.01$ ) were significantly higher for females compared with males, as were the odds of attempted suicide (AOR 5.5, 95\% CI 3.3 - 9.2; $p<0.01$ ).

Factors involving violence were commonly found to be associated with planning and attempting suicide in this study (Table 2) and were similar to other previous studies of suicide. Gender-based violence was a significant risk factor for making a suicide plan and attempting suicide. For instance, learners who reported being physically hurt 1 - 3 times by someone they were dating reported more than twice the likelihood of making a suicide plan (AOR 2.2, 95\% CI 1.4 - 3.6; $p<0.01$ ) and attempting suicide (AOR 2.5, 95\% CI 1.6 - 3.8; $p<0.01$ ) compared with those who did not have this experience.

Table 3 shows that 175 of the female learners (23.9\%) and 42 of the males $(6.5 \%)$ had made a suicide attempt that resulted in their being treated by a doctor or nurse, indicating that females were more vulnerable than males $(p<0.01)$. The suicide attempts that were treated by a doctor or nurse tended to be made by older learners. Compared with learners aged 13 - 15 years, learners aged $16-17$ reported twice as many suicide attempts that resulted in being seen by a doctor or nurse ( $n=97,28.9 \%$ ) (AOR $2.1,95 \%$ CI $1.3-3.4 ; p<0.01$ ), as did those aged 18 - 23 years $(n=45,29.2 \%)$ (AOR 2.1, 95\% CI 1.4 $3.3 ; p<0.01)$.

For male learners, experiencing violence and bullying significantly increased the likelihood of making a suicide attempt that resulted in treatment by a doctor or nurse. Such experiences included being threatened with a weapon on school property (AOR 3.7, 95\% CI 1.9 $7.1 ; p<0.01)$ and being bullied through Facebook or WhatsApp (AOR 3.1, 95\% CI 1.5 - 7.1; $p<0.01$ ).

For female learners, engaging in risk behaviours significantly increased the likelihood of a suicide attempt that resulted in being treated by a doctor or nurse. Risk factors included being physically hurt by someone they were dating ( 1 - 3 times AOR 3.3, 95\% CI 1.9 - 5.7; $p<0.01, \geq 4$ times AOR 10.0, 95\% CI $2.5-40.2 ; p<0.01)$ and number of drinks consumed in the past month (AOR 2.0, 95\% CI 1.4 - 3.0; $p<0.01$ ). Both females (AOR 2.2, 95\% CI $1.4-3.6 ; p<0.01$ ) and males (AOR 2.7, 95\% CI $5-4.7 ; p<0.01$ ) who had used cannabis 
Table 1. Demographic characteristics of the high-school learners*

\begin{tabular}{|c|c|c|c|c|}
\hline & Male & Female & Total & $p$-value \\
\hline Gender & $873(49.6)$ & $886(50.4)$ & 1759 & 0.7 \\
\hline Age (years), mean (SD) & $17.0(1.5)$ & $16.5(1.6)$ & $16.7(1.6)$ & $<0.001$ \\
\hline Age group (years), $n(\%)$ & & & & $<0.001$ \\
\hline $13-15$ & $139(15.9)$ & $284(32.1)$ & $423(24.0)$ & \\
\hline $16-17$ & $417(47.8)$ & $392(44.2)$ & $809(46.0)$ & \\
\hline $18-23$ & $317(36.3)$ & $210(23.7)$ & $527(30.0)$ & \\
\hline Who do you live with, $n(\%)$ & & & & 0.9 \\
\hline Both parents & $245(28.1)$ & $219 / 884(24.8)$ & $464 / 1757$ (26.4) & \\
\hline Father & $59(6.8)$ & $29 / 884(3.3)$ & $88 / 1757(5.0)$ & \\
\hline Mother & $282(32.3)$ & $331 / 884(37.4)$ & $613 / 1757(34.9)$ & \\
\hline Extended/other & $287(32.9)$ & $305 / 884(34.5)$ & $592 / 1757(33.7)$ & \\
\hline Where do you live, $n(\%)$ & & & & 0.2 \\
\hline House & $749 / 843(89.0)$ & $763 / 854(89.3)$ & $1512 / 1697(89.0)$ & \\
\hline Rented room & $22 / 843(2.6)$ & $22 / 854(2.6)$ & $44 / 1697(2.6)$ & \\
\hline Employer & $17 / 843(2.0)$ & $18 / 854(2.1)$ & $35 / 1697(2.1)$ & \\
\hline Informal settlement & $16 / 843(1.9)$ & $27 / 854(3.2)$ & $43 / 1697(2.5)$ & \\
\hline Other & $39 / 843(4.6)$ & $24 / 854(2.8)$ & $63 / 1697(3.7)$ & \\
\hline $\begin{array}{l}\text { Highest educational level of head of household, } \\
n(\%)\end{array}$ & & & & 0.3 \\
\hline Never/primary & $189 / 833(22.7)$ & $221 / 853(25.9)$ & $410 / 1686(24.3)$ & \\
\hline High school & $514 / 833(61.7)$ & $509 / 853(59.7)$ & $1023 / 1686(60.7)$ & \\
\hline Post high school & $130 / 833(15.6)$ & $123 / 853(14.4)$ & $253 / 1686(15.0)$ & \\
\hline Type of work of head of household, $n(\%)$ & & & & 0.011 \\
\hline Professional & $171 / 830(20.6)$ & $134 / 843(15.9)$ & $305 / 1673(18.2)$ & \\
\hline Skilled & $135 / 830(16.3)$ & $119 / 843(14.1)$ & $254 / 1673(15.2)$ & \\
\hline Unskilled & $222 / 830(26.7)$ & $226 / 843(26.8)$ & $448 / 1673(26.8)$ & \\
\hline Not employed & $302 / 830(36.4)$ & $364 / 843(43.2)$ & $666 / 1673(39.8)$ & \\
\hline Municipality, $n(\%)$ & & & & 0.07 \\
\hline A & $160(18.3)$ & $203(22.9)$ & $363(20.6)$ & \\
\hline B & $135(15.5)$ & $114(12.9)$ & $249(14.2)$ & \\
\hline $\mathrm{C}$ & $151(17.3)$ & $155(17.5)$ & $306(17.4)$ & \\
\hline $\mathrm{D}$ & $170(19.5)$ & $146(16.5)$ & $316(18.0)$ & \\
\hline $\mathrm{E}$ & $121(13.9)$ & $112(12.6)$ & $233(13.2)$ & \\
\hline $\mathrm{F}$ & $136(15.6)$ & $156(17.6)$ & $292(16.6)$ & \\
\hline
\end{tabular}

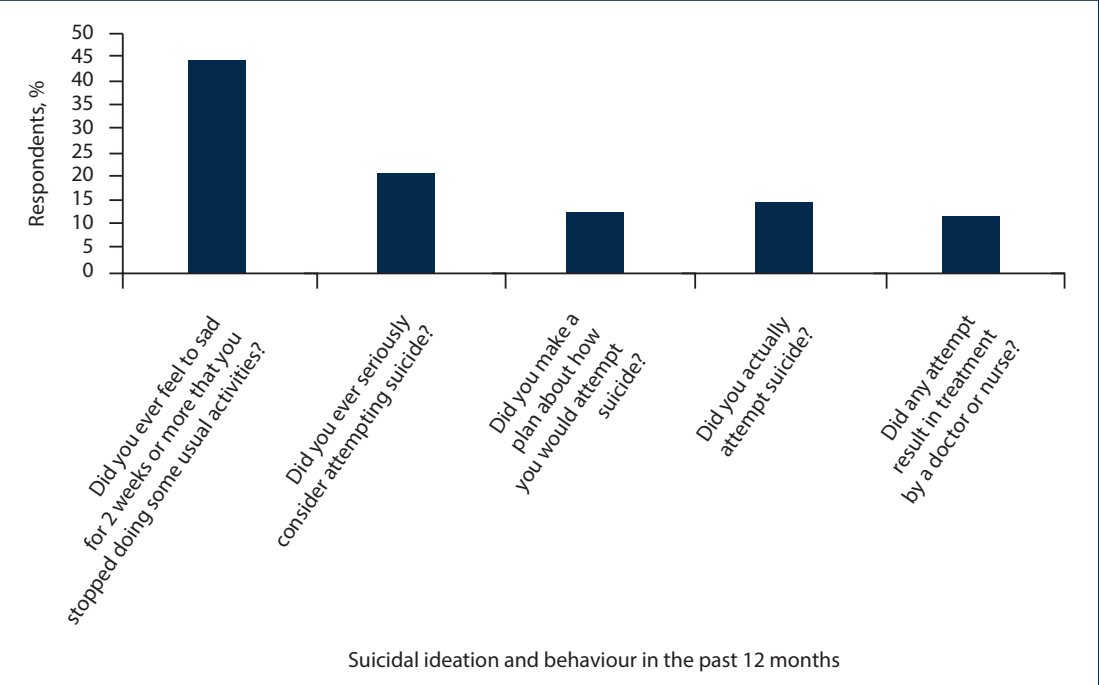

Fig. 1. Graphical representation of the prevalence of suicidal ideation and behaviour in high-school learners. during the 3 months before data collection were more than twice as likely as non-users to make a suicide attempt that resulted in being treated by a doctor or nurse.

\section{Discussion}

Our findings in rural KwaZulu-Natal Province confirm the results of the three national youth behavioural surveys conducted in SA in 2002, 2008 and 2013. ${ }^{[15]}$ We found similar risk factors, such as physical violence and drug abuse, to be associated with suicide plans and suicide attempts. Our study further identified societal violence as an important risk factor that was significantly associated with suicide plans and suicide attempts. Although there are numerous studies on violence, these have not reported on the association between violence and suicide plans and attempts 
Table 2. Planned and attempted suicide during the past 12 months*

\begin{tabular}{|c|c|c|c|c|c|c|}
\hline & \multicolumn{3}{|c|}{ Plan to attempt suicide } & \multicolumn{3}{|c|}{ Attempted suicide } \\
\hline & Yes, $\boldsymbol{n}(\%)$ & Total, $N$ & $\begin{array}{l}\text { AOR, 95\% CI } \\
(p \text {-value })^{\dagger}\end{array}$ & Yes, $n(\%)$ & Total, $N$ & $\begin{array}{l}\text { AOR, 95\% CI } \\
(p \text {-value })^{\dagger}\end{array}$ \\
\hline \multicolumn{7}{|l|}{ Age group (years) } \\
\hline $13-15$ & $36(9.0)$ & 401 & Ref & $43(10.6)$ & 407 & Ref \\
\hline $16-17$ & $119(15.4)$ & 770 & $2.0,1.4-2.8(<0.01)$ & $136(17.3)$ & 785 & $1.9,1.2-2.9(<0.01)$ \\
\hline $18-23$ & $65(12.7)$ & 488 & $1.5,0.9-2.4(0.07)$ & $77(1516)$ & 495 & $1.7,1.1-2.5(0.02)$ \\
\hline Total & $220(13.3)$ & 1659 & & $256(15.2)$ & 1687 & \\
\hline \multicolumn{7}{|l|}{ Gender } \\
\hline Female & $166(19.7)$ & 841 & $5.6,3.6-8.7(<0.01)$ & $196(22.9)$ & 854 & $6.1,37-10.1(<0.01)$ \\
\hline Male & $51(6.2)$ & 818 & ref & $60(7.2)$ & 833 & Ref \\
\hline Total & $217(13.1)$ & 1659 & & $256(15.2)$ & 1687 & \\
\hline \multicolumn{7}{|c|}{$\begin{array}{l}\text { Threatened with a weapon on } \\
\text { school property }\end{array}$} \\
\hline No & $168(11.6)$ & 1447 & Ref & $197(13.4)$ & 1471 & Ref \\
\hline Yes & $49(23.1)$ & 212 & $1.9,1.3-2.6(<0.01)$ & $59(27.3)$ & 216 & $2.1,1.2-3.7(0.02)$ \\
\hline Total & $217(13.1)$ & 1659 & & $256(15.1)$ & 1687 & \\
\hline \multicolumn{7}{|c|}{ Someone you were dating } \\
\hline \multicolumn{7}{|c|}{ physically hurt you } \\
\hline 0 times & $168(11.0)$ & 1522 & Ref & $199(12.9)$ & 1548 & Ref \\
\hline $1-3$ times & $37(33.0)$ & 112 & $2.2,1.4-3.6(<0.01)$ & $44(38.6)$ & 114 & $2.3,1.5-3.6(<0.01)$ \\
\hline$\geq 4$ times & $12(48.0)$ & 25 & $3.4,0.9-12.7(0.06)$ & $13(52.0)$ & 25 & $2.8,0.6-12.6(0.2)$ \\
\hline Total & $217(13.1)$ & 1659 & & $256(15)$ & 1687 & \\
\hline \multicolumn{7}{|c|}{$\begin{array}{l}\text { Someone you were dating forced } \\
\text { you to do sexual things }\end{array}$} \\
\hline $0-1$ time & $204(12.6)$ & 1625 & Ref & $241(14.6)$ & 1651 & Ref \\
\hline$\geq 2$ times & $13(38.2)$ & 34 & $p=0.07$ & $15(41.7)$ & 36 & $1.9,0.4-8.0(0.4)$ \\
\hline Total & $217(13.1)$ & 1659 & & $256(15.2)$ & 1687 & \\
\hline \multicolumn{7}{|c|}{$\begin{array}{l}\text { Have you been bullied on school } \\
\text { property }\end{array}$} \\
\hline No & $125(9.9)$ & 1259 & Ref & $158(12.3)$ & 1280 & Ref \\
\hline Yes & $92(23.0)$ & 400 & $2.1,1.4-3.2(<0.01)$ & $98(24.1)$ & 407 & $1.7,1.1-2.5(0.02)$ \\
\hline Total & $217(13.1)$ & 1659 & & $256(15.2)$ & 1687 & \\
\hline \multicolumn{7}{|c|}{ Have you been bullied through } \\
\hline \multicolumn{7}{|l|}{ Facebook, etc. } \\
\hline No & $156(11.2)$ & 1397 & Ref & $184(13.0)$ & 1420 & Ref \\
\hline Yes & $61(23.3)$ & 262 & $1.9,1.3-2.8(<0.01)$ & $72(27.0)$ & 267 & $1.6,1.6-2.7(<0.01)$ \\
\hline Total & $217(13.1)$ & 1659 & & $256(15.2)$ & 1687 & \\
\hline \multicolumn{7}{|c|}{$\begin{array}{l}\text { Number of alcoholic drinks in past } \\
\text { month }\end{array}$} \\
\hline$\leq 2$ & $165(11.4)$ & 1446 & Ref & $197(13.4)$ & 1473 & Ref \\
\hline$\geq 3$ & $52(24.4)$ & 213 & $1.9,1.2-3.0(<0.01)$ & $59(27.6)$ & 214 & $1.9,1.2-3.2(0.01)$ \\
\hline Total & $217(13.1)$ & 1659 & & $256(15.2)$ & 1687 & \\
\hline \multicolumn{7}{|c|}{ Cannabis use in past 3 months } \\
\hline None & $159(11.4)$ & 1390 & Ref & $190(13.4)$ & 1413 & Ref \\
\hline$\geq 1$ & $58(21.6)$ & 269 & $2.0,1.5-2.7(<0.01)$ & $66(24.1)$ & 274 & $2.0,1.3-2.8(<0.01)$ \\
\hline Total & $217(13.1)$ & 1659 & & $256(15.2)$ & 1687 & \\
\hline \multicolumn{7}{|c|}{ Number of sexual partners in past } \\
\hline \multicolumn{7}{|l|}{3 months } \\
\hline Never had sex & $97(10.0)$ & 966 & Ref & $120(12.2)$ & 982 & Ref \\
\hline $0-2$ & $101(17.4)$ & 580 & $p=0.2$ & $113(19.1)$ & 593 & $p=0.8$ \\
\hline$\geq 3$ & $19(16.8)$ & 113 & $p=0.3$ & $23(20.5)$ & 112 & $p=0.2$ \\
\hline Total & $217(13.1)$ & 1659 & & $256(15.2)$ & 1687 & \\
\hline
\end{tabular}


Table 3. Attempted suicide that resulted in treatment by a doctor or nurse during the past 12 months*

\begin{tabular}{|c|c|c|c|c|c|c|}
\hline & \multicolumn{3}{|c|}{ Females $(175 / 731,23.9 \%)$} & \multicolumn{3}{|c|}{ Males $(42 / 651,6.5 \%)$} \\
\hline & Yes, $n(\%)$ & Total, $N$ & $\begin{array}{l}\text { AOR, 95\% CI } \\
(p \text {-value })^{\dagger}\end{array}$ & Yes, $n(\%)$ & Total, $N$ & $\begin{array}{l}\text { AOR, 95\% CI } \\
(p \text {-value })^{\dagger}\end{array}$ \\
\hline \multicolumn{7}{|l|}{ Age group (years) } \\
\hline $13-15$ & $33(13.7)$ & 241 & Ref & $6(5.4)$ & 111 & Ref \\
\hline $16-17$ & $97(28.9)$ & 336 & $2.1,1.3-3.4(<0.01)$ & $22(6.7)$ & 328 & $0.9,0.3-3.0(0.8)$ \\
\hline $18-23$ & $45(29.2)$ & 154 & $2.1,1.4-3.3(<0.01)$ & $14(6.6)$ & 212 & $0.6,0.2-2.2(0.4)$ \\
\hline Total & $175(23.9)$ & 731 & & $42(6.4)$ & 651 & \\
\hline \multicolumn{7}{|c|}{$\begin{array}{l}\text { Threatened with a weapon on } \\
\text { school property }\end{array}$} \\
\hline No & $151(22.4)$ & 673 & Ref & $22(4.1)$ & 534 & Ref \\
\hline Yes & $24(41.4)$ & 58 & $p=0.6$ & $20(17.1)$ & 117 & $3.7,1.9-7.1(<0.01)$ \\
\hline Total & $175(63)$ & 731 & & $42(6.4)$ & 651 & \\
\hline \multicolumn{7}{|c|}{$\begin{array}{l}\text { Someone you were dating } \\
\text { physically hurt you }\end{array}$} \\
\hline 0 times & $130(19.9)$ & 653 & Ref & $37(6.1)$ & 609 & Ref \\
\hline $1-3$ times & $34(53.1)$ & 64 & $3.3,1.9-5.7(<0.01)$ & $4(12.1)$ & 33 & $p=0.7$ \\
\hline$\geq 4$ times & $11(78.6)$ & 14 & $10.0,2.5-40.2(<0.01)$ & $1(11.1)$ & 9 & $p=0.5$ \\
\hline Total & $175(23.9)$ & 731 & & $42(6.4)$ & 651 & \\
\hline \multicolumn{7}{|c|}{$\begin{array}{l}\text { Someone you were dating } \\
\text { forced you to do sexual things }\end{array}$} \\
\hline $0-1$ times & $168(23.4)$ & 504 & Ref & $38(6.0)$ & 637 & Ref \\
\hline$\geq 2$ times & $7(50.0)$ & 14 & $p=0.6$ & $4(28.6)$ & 14 & $p=0.1$ \\
\hline Total & $175(23.9)$ & 731 & & $42(6.4)$ & 451 & \\
\hline \multicolumn{7}{|c|}{$\begin{array}{l}\text { Have you been bullied on } \\
\text { school property }\end{array}$} \\
\hline No & $109(20.1)$ & 543 & Ref & $22(4.4)$ & 501 & Ref \\
\hline Yes & $66(35.3)$ & 187 & $p=0.1$ & $20(13.3)$ & 150 & $p=0.2$ \\
\hline Total & $175(23.9)$ & 731 & & $42(6.4)$ & 651 & \\
\hline \multicolumn{7}{|c|}{$\begin{array}{l}\text { Have you been bullied } \\
\text { through Facebook, etc. }\end{array}$} \\
\hline No & $133(21.0)$ & 634 & Ref & $24(4.6)$ & 526 & Ref \\
\hline Yes & $42(43.3)$ & 97 & $p=0.1$ & $18(14.4)$ & 125 & $3.1,1.5-7.1(0.01)$ \\
\hline Total & $175(23.9)$ & 731 & & $42(6.4)$ & 651 & \\
\hline \multicolumn{7}{|c|}{$\begin{array}{l}\text { Number of alcoholic drinks } \\
\text { in past month }\end{array}$} \\
\hline$<2$ & $141(21.2)$ & 665 & Ref & $32(5.9)$ & 543 & Ref \\
\hline$\geq 3$ & $34(51.5)$ & 66 & $2.0,1.4-3.0(<0.01)$ & $10(9.2)$ & 108 & $p=0.9$ \\
\hline Total & $175(23.9)$ & 731 & & $42(6.4)$ & 651 & \\
\hline \multicolumn{7}{|c|}{$\begin{array}{l}\text { Cannabis use in past } 3 \\
\text { months }\end{array}$} \\
\hline None & $141(21.3)$ & 663 & Ref & $23(4.5)$ & 506 & Ref \\
\hline$\geq 1$ & $34(50.0)$ & 68 & $2.2,1.4-3.6(<0.01)$ & $19(13.1)$ & 145 & $2.7,5-4.7(<0.01)$ \\
\hline Total & $175(23.9)$ & 731 & & $42(6.4)$ & 651 & \\
\hline \multicolumn{7}{|c|}{$\begin{array}{l}\text { Number of sexual partners in } \\
\text { past } 3 \text { months }\end{array}$} \\
\hline Never had sex & $94(19.2)$ & 489 & Ref & $10(3.0)$ & 329 & Ref \\
\hline $0-2$ & $77(32.3)$ & 238 & $p=0.9$ & $20(8.3)$ & 240 & $p=0.6$ \\
\hline$\geq 3$ & $4(100)$ & 4 & - & $12(14.6)$ & 82 & $p=0.4$ \\
\hline Total & $175(23.9)$ & 731 & & $42(6.4)$ & 651 & \\
\hline
\end{tabular}

among adolescents. ${ }^{[17,18]}$ Violence is not a new phenomenon in SA, as we reported in our previous article, ${ }^{[13]}$ and it affects both adults and young people. For instance, the SA school violence national survey reported a high prevalence of school violence among high-school learners, including acts of harassment, sexual assaults, physical violence and cyber bullying. ${ }^{[11]}$ Researchers agree that the level of 
violence in a school mirrors the state of the community where the school is situated. Learners grow up in homes and communities where they are exposed to intimate partner violence between their parents and caregivers. ${ }^{[11,12]}$ They are further exposed to community norms that encourage acts of violence. ${ }^{[19]}$ These learners therefore engage in similar relationships, with negative consequences such as unplanned pregnancies ${ }^{[3,4]}$ and physical ${ }^{[19]}$ and emotional abuse. ${ }^{[19]}$ A study of traumatic events and behaviour conducted in SA found sexual violence to be a predictor of lifetime suicide attempts. ${ }^{[17]}$ We found that female learners who reported being physically hurt by someone they were dating had a significantly increased likelihood of suicide plans and attempts, whereas the main risk factors for male learners were being threatened with a weapon on school property and being bullied in school and through Facebook and WhatsApp. This constant exposure to violence is a major concern emerging from this study. Bullying through Facebook and WhatsApp is an added complication, being uncontrollable because anyone with a data bundle can access these platforms at any time.

Previous studies on suicide conducted globally in countries including SA, ${ }^{[20]}$ South India ${ }^{[21]}$ and the USA ${ }^{[22]}$ show higher suicide rates in male adolescents than in females. In contrast, we found that female learners had higher rates of making a suicide plan, actual suicide attempts and suicide attempts that resulted in being treated by a doctor or nurse.

We also found significant levels of substance abuse among learners who made suicide plans and attempts. For both male and female learners, using cannabis during the 3 months before the survey significantly increased the likelihood of a suicide attempt that resulted in treatment by a doctor or nurse, while for females an additional risk factor was consuming three or more drinks of alcohol in the month before the survey. Our results support previous studies on alcohol and drug abuse among youth. ${ }^{[9,15-16]}$ Of concern is the fact that in SA, rules and regulations regarding alcohol consumption have been in existence for some time, ${ }^{[12]}$ but enactment does not appear to be producing positive outcomes. There is therefore an urgent need to review alcohol policy so that it can be effective in regulating the use of alcohol, especially by individuals aged $<18$ years. There is evidence that the suicide rate in SA is higher than in some other countries in sub-Saharan Africa. ${ }^{[4]}$ It is estimated that suicide will contribute $>2 \%$ to the global burden of disease by $2020 .{ }^{[21]}$ Rigorous interventions to curb suicide in $\mathrm{SA}$ are required.

\section{Study limitations}

The study increased our knowledge of adolescent suicide and suicidal ideation, but has some limitations. Learners completed a confidential self-administered questionnaire, although a researcher was reading out questions. A limitation was that the learners' responses were self-reports of their behaviour. Some learners may have misreported some items. The survey was only based in high schools. Caution should be exercised in generalising the findings to the general population of learners. However, our results suggest that socioecological theory-based suicide prevention interventions are required to reduce suicide rates among learners. ${ }^{[11]}$ The prevalence of risk behaviours and consequent suicidality in learners requires a system for early detection. For example, those who use cannabis and alcohol, or who bully or are bullied on school property or through Facebook and WhatsApp, need to be identified and enrolled in innovative interventions.

\section{Conclusion}

The prevalence of suicide attempts among SA learners is high and is influenced by multiple factors, including the high-risk environments in which they live and a range of risk behaviours. Similar risk factors, such as physical violence and drug abuse, were found to be associated with suicide plans and suicide attempts in previous studies. An important new discovery was societal violence, an additional risk factor that was found to be significantly associated with suicide plans and suicide attempts. Routine surveillance in rural schools is required to monitor suicidal ideation and behaviour among learners. Of concern is that there are few primary prevention interventions for violence in SA, and they do not specifically focus on suicide. Most are research based, and most are not rolled out to the larger population. In schools, the Life Orientation learning area, which is compulsory in government schools, covers a range of life skills, but it is evident that these have not adequately empowered learners. We found that female learners were at particular risk of attempting suicide, so interventions targeting them are urgently required.

Violence, gender-based violence and drug use are regulated in SA, but despite this, prevalence rates are high and the situation is further complicated by the fact that they are associated with suicide in school learners. ${ }^{[12]} \mathrm{A}$ review of the responses to alcohol and sexual assault policies is urgently required to promote and ensure proper implementation.

Finally, our results showed that many learners who attempt suicide are seen by a doctor or a nurse. Research is required to explore how these doctors and nurses manage the attempted suicide cases they see, as this offers an opportunity for prevention of further attempts.

Acknowledgements. We thank the provincial Department of Education, uMgungundlovu district office and the 16 high schools for allowing us to conduct the survey, and the grade 10 learners for answering the questionnaires. We also thank facilitators from the AIDS Foundation for assisting during the data collection phase.

Author contributions. The research was undertaken for the requirements of NK's Doctorate in Public Health. NK was the principal investigator and conceptualised the study together with MT. CC participated in data cleaning and analysis. All the authors reviewed the final draft of the article. Funding. The study was funded by the University of KwaZulu-Natal, via a College of Health Sciences scholarship awarded to NK.

Conflicts of interest. None.

1. Shilubane HN, Ruiter RAC, Bos AER, van den Borne S, James S, Reddy PS. Psychosocial determinants of suicide attempts among black South African adolescents: A qualitative analysis. J Youth Stud 2011:15(2):177-189. https://doi.org/10.1080/13676261.2011.634400

2. Cooper D, de Lannoy A, Rule C. Youth health and well-being: Why it matters. In: De Lannoy A, Swartz S, Lake L, Smith C, eds. South African Child Gauge. Cape Town: Human Sciences Research Council, 2015:60.

3. Ammerman S, Ryan S, Adelman WP, Committee on Substance Abuse, Committee on Adolescence. The impact of marijuana policies on youth: Clinical, research, and legal update. Pediatrics 2015;135(3):e769-e785. https://doi.org/10.1542/peds.2014-4147

4. Schlebusch L. Suicide prevention: A proposed national strategy for South Africa: Review. Afr J Psychiatry 2012;15(6):436-440. https://doi.org/10.4314/ajpsy.v15i6.56

5. Shilubane HN, Ruiter RA, van den Borne B, Sewpaul R, James S, Reddy PS. Suicide and related health risk behaviours among school learners in South Africa: Results from the 2002 and 2008 national youth risk behaviour surveys. BMC Public Health 2013:13(1):926. https://doi.org/10.1186/1471-2458-13-926 6. Statistics South Africa. Mortality and Causes of Death in South Africa 2015: Findings from Death 6. Statistics South Africa. Mortality and
Notifications. Pretoria: Stats SA, 2015.

Detifations. Pretoria: Stats SA, 2015. - 2014. S Afr Med J 2017;107(12):1132-1136. https://doi.org/10.7196/SAMJ.2017.v107i12.12652.
.

8. Seedat M, van Niekerk A, Jewkes R, Suffla S, Ratele K. Violence and injuries in South Africa: Prioritisin 8. Seedat M, van Niekerk A, Jewkes R, Suffla S, Ratele K. Violence and injuries in South Africa: Prioritising
an agenda for prevention. Lancet 2009;374(9694):1011-1022. https://doi.org/10.1016/S01406736(09)60948-X

9. Burrows S, Vaez M, Laflamme L. Sex-specific suicide mortality in the South African urban context: The role of age, race, and geographical location. Scand J Public Health 2007;35(2):133-139. https://doi. org/10.1080/14034940600975773

10. Lardier DT jr, Barrios VR, Garcia-Reid P, Reid RJ. Suicidal ideation among suburban adolescents: The influence of school bullying and other mediating risk factors. J Child Adolesc Mental Health 2016;28(3):213-231. https://doi.org/10.2989/17280583.2016.1262381

11. Liang H, Flisher A, Lombard C. Bullying, violence, and risk behavior in South African school students. Child Abuse Negl 2007;31(2):161-171. https://doi.org/10.1016/j.chiabu.2006.08.007

12. Burton P, Leoschut L. School Violence in South Africa: Results of the 2012 National School Violence Study Cape Town: Centre for Justice and Crime Prest of 2013 . htp uploads/2/7/8/4/27845461/monograph12-school-violence-in-south_africa.pdf (accessed 30 March 2018). 
13. Khuzwayo N, Taylor M, Connolly C. Prevalence and correlates of violence among South African high school learners in uMgungundlovu District municipality, KwaZulu-Natal, South Africa. S Afr Med J 2016;106(12):1216-1221. https://doi.org/10.7196/SAMJ.2016.v106i12.10969

14. Sigfusdottir ID, Asgeirsdottir BB, Gudjonsson GH, Sigurdsson JF. Suicidal ideations and attempts among adolescents subjected to childhood sexual abuse and family conflict/violence: The mediating role of anger adolescents subjected to childhood sexual abuse and family conflict/violence: The mediating role of anger
and depressed mood. J Adolesc 2013;36(6):1227-1236. https:///doi.org/10.1016/.adolescence.2013.10.001 15. Reddy SP, James S, Sewpaul R, et al. Umthente Uhlaba Usamila: The 3rd South African National Youth 5eddy SP, James S, Sewpaul R, et al. Umthente Uhlaba Usamila: The 3rd South African N
Risk Behaviour Survey 2011. Cape Town: South African Medical Research Council, 2013.

Risk Behaviour Survey 2011. Cape Town: South African Medical Research Council, 2013 .
6. Shaikh MA, Lloyd J, Acquah E, Celedonia KL, Wilson ML. Suicide attempts and behavioral correlates 6. Shaikh MA, Lloyd J, Acquah E, Celedonia KL, Wilson ML. Suicide attempts and behavioral correlates
among a nationally representative sample of school-attending adolescents in the Republic of Malawi. BMC Public Health 2016;16(1):843. https://doi.org/10.1186/s12889-016-3509-8

17. Sorsdahl K, Stein DJ, Williams DR, Nock MK. Associations between traumatic events and suicidal behaviour in South Africa. J Nerv Ment Dis 2011;199(12):928. https://doi.org/10.1097/ NMD.0b013e3182392c39

18. Espelage DL, Basile KC, de la Rue L, Hamburger ME. Longitudinal associations among bullying, homophobic teasing, and sexual violence perpetration among middle school students. J Interpers Violence 2015;30(14):2541-2561. https://doi.org/10.1177/0886260514553113
19. Burrows S, Laflamme L. Assessment of accuracy of suicide mortality surveillance data in South Africa: Investigation in an urban setting. Crisis 2007;28(2):74-81. https://doi.org/10.1027/0227-5910.28.2.74

20. Pitman A, Krysinska K, Osborn D, King M. Suicide in young men. Lancet 2012;379(9834):2383-2392. https://doi.org/10.1016/S0140-6736(12)60731-4

21. Sudhir Kumar CT, Mohan R, Ranjith G, Chandrasekaran R. Gender differences in medically serious suicide attempts: A study from South India. Psychiatry Res 2006;144(1):79-86. https://doi.org/10.1016/j psychres.2005.11.012

22. Brener ND, Krug EG, Simon TR. Trends in suicide ideation and suicidal behaviour among high schoo students in the United States, 1991 - 1997. Suicide Life Threat Behav 2000;30:304-312. https://doi org/10.1111/j.1943-278X.2000.tb01097.x

Accepted 1 December 2017 